\title{
THE INFLUENCE OF HEREDITY IN EXOPHTHALMIC GOITRE.
}

BY

\author{
E. A. COCKAYNE, D.M., F.R.C.P.
}

Physician, Middlesex Hospital ;

Physician to Outpatients, Hospital for Sick Children, Gt. Ormond St., London.

The tendency in recent years has been to look upon exophthalmic goitre as a disease due to some acquired cause such as an infection of the teeth or tonsils, or to mental worry, and to disregard the inborn liability of certain individuals to develop the condition. Sir Archibald Garrod's Huxley Lecture on Diathesis delivered last November has been a timely reminder that in many diseases not actually hereditary, an inborn weakness of some organ may be inherited and render it susceptible to some particular disorder. This appears to be true of the thyroid gland and exophthalmic goitre.

A large number of families have been reported in which more than one member of the same generation has been affected, or in which the disease has occurred in several members of successive generations. Unfortunately in very few of these families has a complete pedigrec been given, but in none of those in which such a pedigree is available does the number with exophthalmic goitre correspond with that expected of a Mendelian dominant. In a number of cases it has been met with in a parent and one or more of the children, and in two, reported by Cantilena and Sottas, it affected parent, child, and grandchild. This shows that, though it does not behave strictly as a dominant, it cannot be a recessive character.

In the family $I$ am recording there were five females and thre s males, all apparently healthy, in the first generation. The eldest of the daughters had two children, both girls ; the elder was normal, but of her two children the first a boy, was normal, and the second, a girl of eight, whose illness I am describing later, had exophthalmic goitre; the younger had cxophthalmic goitre which started at the age of forty years, and her only daughter who was twenty years of age and unmarried was healthy. The second daughter of the first generation had two children, a son and a daughter. The son is apparently normal, but his only child, a boy aged ten years, has severe Graves's disease, for which he has been treated by X-rays. Both father and son have lived for many years in Canada, so that environment can have had no influence in causing the disease in these two branches of the family. The daughter, aunt. of the little boy with Graves's disease, developed Graves's disease at the age of twenty-four, and has two healthy children, a girl who was born before her mother's symptoms appeared and a boy who was born after they appearcd. Unfortunately it has been impossible to obtain any information about the other members of the first generation (Fig. 1). 
The girl mentioned above was aged eight years and three months, when she was seen at the Hospital for Sick Children, Great Ormond Street, on February 24th, 1927. There was a history that goitre with rapid pulse had been noticed first. in the previous November. She had slight exophthalmos, von Graefe's sign, uniform enlargement of the thyroid gland, a fine tremor of the hands, and a pulse rate of 160 at rest. She was extraordinarily excitable, speaking very quickly and continually altering her position. She was thin and her weight, which had gone down, was $53 \mathrm{lb}$. Her skin was moist and she was rather flushed. She improved considerably in the hospital under the care of Dr. Robert Frew, who has kindly given me permission to publish these notes, and had no treatment there except rest in bed. She was looked after very carefully after her discharge from the hospital, and with getting up late, lying down in the afternoon, and leading a quiet life, continued to make good progress. In July, 1927, she weighed 591 lb. ; her pulse rate was akout 100 at rest though the rate increased readily after exertion or with emotion. She was much less excitable, but she still showed all the signs of the disease.

It is interesting that the phenomenon of anticipation which is so common in hereditary diseases of a degenerative nature, is also shown in this disease which belongs to another category. It is probably due to this that a much

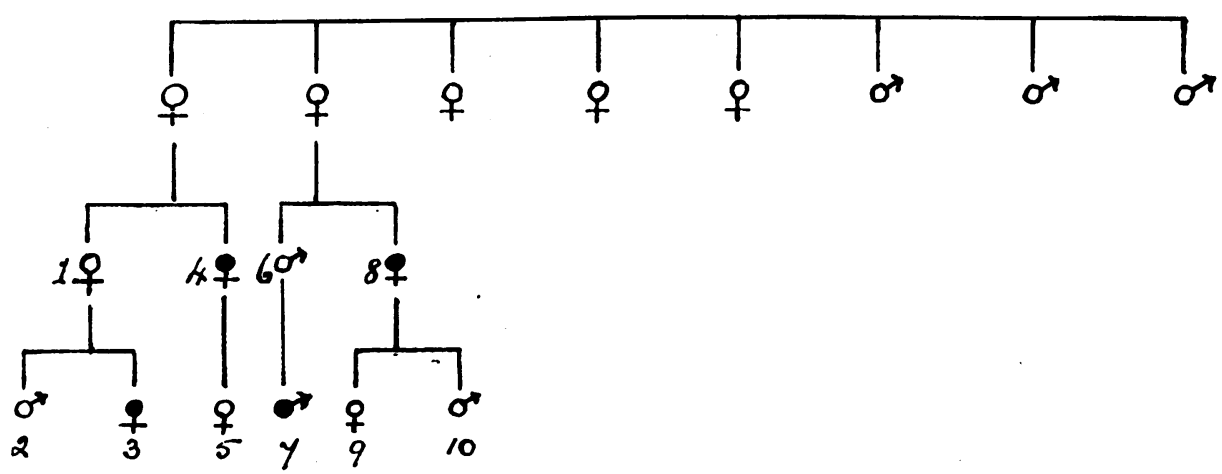

3. Onset at 7 years.

7. Onset before 10 years.

4. Onset at 40 jears.

8. Onset at 24 years.

Fig. 1.-Author's CASE.

higher percentage of cases in children occurs in hereditary than in sporadic exophthalmic goitre. This family adds another example of anticipation to those already published. In the family described by Zelener the disease began at the age of thirty-three in the mother, but was fully developed at twenty-seven and twenty-five in her two daughters and earlier still in her two sons. In Climenko's family (Fig. 2.) it appeared at thirty-nine in the first generation, at twenty-seven in the second, and it was already present at the ages of ten and six years in two of the children of the third generation. In Raillet's family the father did not develop Graves's disease until after the birth of his daughter, but in her case it was present at the age of seven and a half years. Solbrig describes a family in which the mother developed the disease in adult life but her son already showed the signs at eight years of age. In the family reported by Moss the mother had the disease as an adult, her eldest child, a boy of eleven years, had developed it, her secondchild, agirl of five, washealthy, 
and her third child was beginning to show the early signs. Kronthal.describes a family in which the mother and her twelve year old child had Graves's disease, her eight year old daughter was healthy, and five other children had died in the first years of life. Rosenberg gives an account of a family in which the

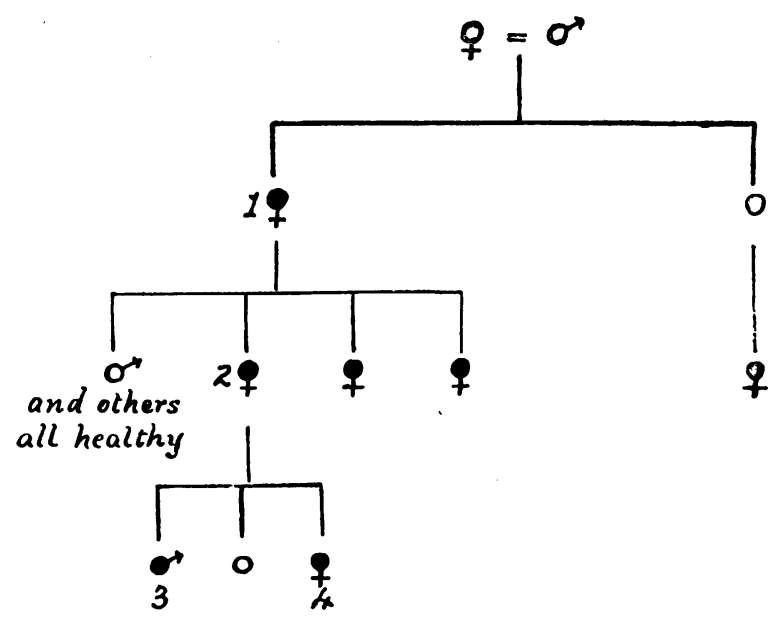

1. Onset at 39 years. $\quad 3$. Disease present at 10 years.

2 . Onset at 27 years. 4 . Disease present at 6 years.

Fig. 2. - Climenko's Case.

father and two daughters had the disease, the younger developing exophthalmos at eight and all the other signs later; she married a man whose mother and two sisters had Graves's disease, and of their family of eleven children ten were stillborn or died in infancy, and only one survived. In the family described

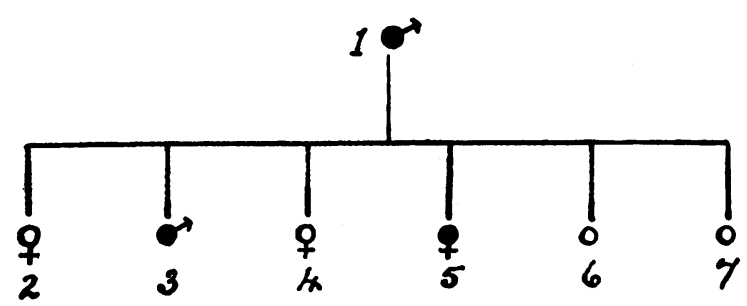

1. Aged 43, exophthalmos and nervousness.

2. Aged 19.

3. Age not stated, exophthalmos and tachycardia.

Fig. 3.-Nicoll's Case.

4. Aged 14, tachycardia.

5. Aged 10, typical Graves's disease.

6. Aged 6.

7. Aged 3.

by Nicoll (Fig. 3.), the father developed exophthalmos and nervousness as an adult but no tachycardia, his eldest son had exophthalmos and tachycardia, his second daughter aged fourteen had tachycardia, his third daughter aged ten had all the signs of Graves's disease, and his three remaining children were 
normal. In the case of the families collected by Curtin, though the age of onset is not given, it is noteworthy that in the second generation the disease was frequently present in childhood or at puberty. I have been unable to obtain access to the publication in which Dubreuil-Chambardel gives an account of a family in which four out of eight members were affected in three generations, but the fact that two were children, aged seven and four years respectively, suggests that this family also exhibited the phenomenon of anticipation.

Even in hereditary cases the disease may only become manifest after puberty and sometimes not until middle age or later. This is well shown in the family described by Osterreicher. Graves's disease appeared in three generations and affected eleven out of sixteen members of the family, but the symptoms did not develop until late adult life. In the family described

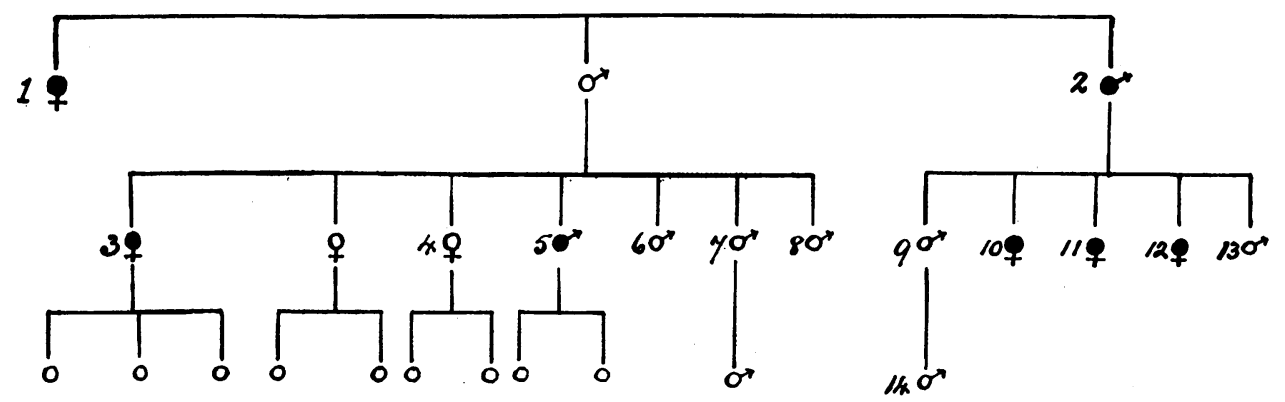

1. Died at 70 years.

2. Died at 57 years.

3. Aged 49.

4. Aged 43 .

5. Agad 39.

6. Aged 35.

7. Aged 30.

8. Aged 24.

9. Aged 45.

10. Died of pulmonary tuberculosis, aged 36 .

11. Aged 41, no children, married.

12 Aged 29, no children, married.

13. Killed in 1914.

14. Aged 20.

Fig. 4.-Souques and Lermuyez C.ase.

by Souques an 1 Lermoyez (Fig. 4.), the disease cieveloped before middle age. In other hereditary cases the onset is earlicr, and the disease may appear in childhood, but it is almost unknown as a congenital malady. Of the two cases of congenital Graves's disease recorded as having occurred in the children of mothers suffering from the same condition, only that reported by Clifford White seems to have been a genuine example. The one reported by Schmauch appears to have been a case of oxycephaly in the baby of a woman with Graves's disease.

Transmission frequently occurs through apparently normal individuals and the disease affects grandparent and grandchild, or aunt and niece. In many instances two or more children have the disease whilst the parents appear to be healthy. All four affected members of the family I am reporting had apparently healthy parents. Either we must alter our clinical conception of Graves's disease altogether, and accept the most trifling departures from the normal 
as evidence of its presence, or we must admit that Graves's disease itself is not hereditary. The second alternative is the more reasonable. The facts that the disease is so rarely present at birth and is so variable in its date of onset, and that it is so often transmitted by apparently healthy parents, are most easily explained by supposing that a constitutional weakness of the thyroid gland, a thyroid diathesis, rather than Graves's disease itself, is inherited. If this is accepted, the pedigrees are no longer difficult to explain on the Mendelian theory. The constitutional weakness of the gland is inherited as a dominant, and some of those who inherit it may remain apparently normal, while others may develop any or all the signs and symptoms of the disease.

This view of its ætiology is supported by the observations of Curtin in America and of Pern in Australia. Both have noticed its great frequency in certain families living in areas where endemic goitre is common, and Curtin has collected records of no less than thirty-five families in which the disease has affected brothers and sisters or parent and child. Whether it is deficiency of iodine in the soil, or infected drinking water, or both, that has a deleterious effect on the thyroid gland in these regions, there can be no doubt that something in the local conditions acts injuriously on the gland. The large number of hereditary cases in these districts is explicable on the ground that this injurious influence causes many with the diathesis to develop Graves's disease, who had they lived elsewhere would not have done so, but would have been regarded as normal individuals.

\section{REFERENCES.}

Climenko, H., Arch. Neur. \& Psychiat., Chicago, 1920, III, 530.

Curtin, R. G., Internat. Clin., Philad., 1897, IV, 78.

Dubreuil-Chambardel, Province Medicale, 1907.

Garrod, A. E., Brit. Med. J., Lond. 1927, ii, 967.

Kronthal, P., Klin. Wchnschr. Berlin, 1893, XXX, 650.

Moss, M. I., New York State J. Med., N.Y., 1914, XCIX, 482.

Nicoll, M., Med. Record., N.Y., 1909, LXXV, 667.

Osterreicher, F., Wien. Med. Presse, Vienna, 1884, XI, 336.

Pern, S., Med. J. Austral., Sydney, 1911-1912, n.s. I, 516.

Raillet, M. G., Bull. et mém. Soc. méd. d. hôp. de Paris, Paris, 1914, XXXVIJ, 708.

Rosenberg, J., Med. Record. N.Y., 1890, XXXVIII, 605.

Schmauch, G., Amer. J. Obst. \& Gynec., N.Y., 1909, LX, 1.

Souques and Lermoyez, J., Rér. neurol., Paris, 1919, XXVI, 20.

White, Clifford, Proc. Roy. Soc. Med., Lond., 1912, V, (Obst. and Gyn. Sect.), 247.

Zelener, quoted by Schulmann, E. Thèses de Paris, 1917-1918, No. 14, 46. 